\title{
O SISTEMA ORÓS-JAGUARIBE NO CEARÁ, NE DO BRASIL
}

\author{
CLÓVIS VAZ PARENTE \& MICHEL HENRIARTHAUD
}

\begin{abstract}
THE ORÓS-JAGUARIBE SYSTEM IN CEARÁ, NORTHEASTERN BRAZIL The Orós-Jaguaribe System is a peculiar geotectonic unit in the Borborema Province (NE Brazil) framework. It contains two linear mobile belts, whose evolution began c.a. $1.9 \mathrm{Ga}$ ago, overlying an older basement characterized by high amphibolite metamorphism and tangential tectonics. In contrast with its basement, the System contains essentially metavolcano-sedimentary sequences intruded by acid and basic magmatic rocks metamorphosed under low greenschist to granulite fácies and displays a strike-slip deformation pattern of brasiliano age (c.a $600 \mathrm{Ma}$ ). The metasediments are essentially pelitic with important intercalation of semi-mature lenticular quartzite, carbonatic quartzite, calcsilicate rocks and calcitic/dolomitic/magnesitic marbles. The Orós Belt exhibitsan inverted distríbution: volume and extension of detritic sediments, essentially quartzite, decrease south-westward, whereas carbonates, essentially calcitic marbles, show a significant increase. These ones become more, magnesitic north-eastward by a differentiation chemical process (elimination of $\mathrm{Ca}$ that precipitate as calcic, calci-magnesitic carbonates or sulfates). These relationships are consistent with a paralic/deltaic system. The acid metaplutonic and metavolcanic rocks are dominantly alkaline or sub-alkaline, characteristic of an intracratonic setting.The lithologic association and distríbution of the metasediments (essentially the basal ones) are shelf type, preceding rift stage, which is associated with an intense magmatism.
\end{abstract}

RESUMO O Sistema Orós-Jaguaribe é uma unidade geotectônica ímpar dentro do domínio da Província Borborema. Ele é composto por duas faixas lineares móveis, cuja evolução iniciou-se em torno de 1,9 Ga, sobre um embasamento mais antigo, metamorfizado em fácies anfibolito alto e marcado por uma deformação tangencial. Contrastando com o embasamento, o Sistema, constituído sobretudo por sequências metavulcanosedimentares recortadas por intrusões ácidas e máficas, foi metamorfizado em condições que variam de xisto verde baixo a granulito e deformado em regime transcorrente durante o Ciclo Brasiliano. Os metassedimentos são sobretudo pelíticos e englobam importantes intercalações lenticulares de quartzitos quase maturos, quartzitos carbonosos, rochas cálcio-silicáticas e mármores calcíticos, dolomíticos e magnesíticos. Na Faixa Orós, esta associação tem uma distribuição inversa: os sedimentos detríticos, particularmente os quartzitos, diminuem em extensão e volume em direção a sudoeste, enquanto os carbonatos são mais abundantes, particularmente os mármores calcíticos. Estes últimos tornam-se mais magnesianos em direção a nordeste, através de um processo de diferenciação química (eliminação do Ca que teria precipitado sob forma de carbonato cálcico ou cálcico-magnesiano ou mesmo de sulfatos). Tais relações caracterizam um sistema misto parálico-deltáico. As rochas ortoderivadas, sobretudo as ácidas, são dominantemente de natureza alcalina a subalcalina, características de ambiente intracratônico. A associação litológica e a organização dos metassedimentos, sobretudo os basais, indica que eles se depositaram em um ambiente plataformal e/ou para-plataformal antecedendo um estágio rift associado a um intenso magmatismo.

INTRODUÇÃO O Sistema Orós-Jaguaribe está localizado na porção centro-sul da Província Borborema (Almeida et al. 1977), Nordeste do Brasil (Fig. 1) e representa parte do Sistema Jaguaribeano de Brito Neves (1975) e Santos \& Brito Neves (1984). Apresenta-se, atualmente, como uma zona linear contínua, de forma sigmoidal, de perto de $500 \mathrm{~km}$ de extensão, constituída por duas sequências meta vulcano-sedimentares marginais lineares, paralelas, separadas por porções de embasamento mais antigo. Sua largura é de pouco mais de $15 \mathrm{~km}$ na sua parte mais estreita (região de Orós-CE) e deve ultrapassar $75 \mathrm{~km}$ nas suas porções mais largas. Sua maior extensão territorial encontra-se no Estado do Ceará, mas ele penetra nos Estados do Rio Grande do Norte e Piauí.

Este Sistema deve representar parte de uma unidade muito mais extensa, com possíveis correlações na África, no Espinhaço/Chapada Diamantina, na Amazónia (Grupo Uatumã), como sugerido por Caby \& Arthaud (1986), Sá (1991) e Van Schmus et al. (1995). Ele recebeu, na literatura, várias denominações (Faixa Orós, Sequência Orós, Faixa OrósJaguaribe, Sistema de Dobramento Jaguaribeano, etc,...), as mais recentes influenciadas pela concentração progressiva dos trabalhos numa porção restrita da faixa metavulcano-sedimentar da região de Orós (CE).
HISTÓRICO No mapa geológico do Ceará, escala 1:500.000, sintetizado por Cavalcante et al (1983), as rochas do Sistema Orós-Jaguaribe são agrupadas sob a denominação de "Metamorfitos da Zona de Orós" e atribuídas ao Grupo Ceará, unidade que congrega a maior parte das sequências metassedimentares do Precambriano cearense, sendo considerada como de idade paleo a mesoproterozóica.

Santos et al. (1984) utilizaram a denominação de Complexo Orós para designar uma sequência essencialmente para-derivada, de baixo grau metamórfico, incluindo algumas rochas ortoderivadas (metamáficas e ultramáficas) presente na região de Orós, Ce.

$\mathrm{O}$ càráter metavulcano-sedimentar dos "Metamorfitos da Zona de Orós" foi reconhecido por Braga \& Mendonça (1984) e Mendonça \& Braga (1987), que sugerem a existência de duas faixas vulcano-sedimentares distintas e paralelas: as Sequências de Orós e de Jaguaribe, separadas por um embasamento gnáissico-migmatítico. Estes autores seguem Cavalcante et al. (1983) e correlacionam estas faixas com o Grupo Ceará.

Caby \& Arthaud (1986), referindo-se às rochas da região de Orós, chamam a atenção para a semelhança dos ortognaisses alcalinos, sub-alcalinos e sieníticos com ortognaisses do Cinturão Panafricano do Oeste da África ("Série dos Quar- 


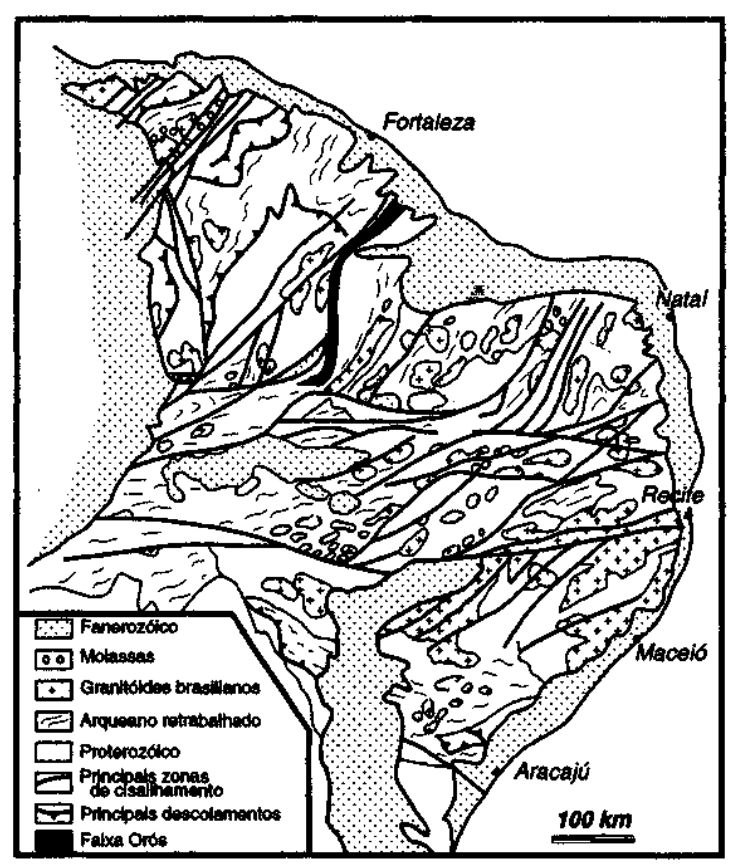

Figura J - Mapa geológico simplificado da Província Borborema (baseado em Santos \& Brito Neves 1984 e Caby et al 1991

Figure 1 - Simplified geologic map of the Borborema Province (based on Santos \& Brito Neves 1984 and Caby et al. 1991)

tzitos do Proterozóico Terminal Inferior"), datados de 1,75 a 1,7 Ga (Caby \& Andreopoulos-Renaud 1983), sendo interpretados, naquela região, como sills e lacólitos pré-metamórficos. Estes ortognaisses são considerados, por Caby \& Arthaud (1986), cpmo tendo uma história tectono-termal monocíclica, assim como boa parte dos metassedimentos que constituem o Grupo Ceará, contrapondo-se a vários autores que assumem uma história policíclica, transamazônica e brasiliana, para a maior parte das supracrustais da Provincia Borborema (ver, $p$. ex. Jardim de Sá 1984).

Macedo et al (1988) e Sá et al (1988), usando a geocronologia (método $\mathrm{Rb} / \mathrm{Sr}$ ), confirmam a idade sugerida por Caby \& Arthaud (1986) para as rochas magmáticas da Faixa Orós e adotam também, para elas, um modelo de evolução monocíclica.

Os trabalhos posteriores de Sá (1991), Sá \& Bertrand (1992) e Sá et al (1995), por exemplo, detalharam vários aspectos da geologia da Faixa Orós nas proximidades da cidade homónima: cartografia, geocronologia, estratigrafia, geoquímica das rochas magmáticas associadas, caracterização e geocronologia dos embasamentos marginais, etc..., levando à formalização de uma proposta de modelo evolutivo para esta faixa (Sá 1991). Neste modelo, a história desta faixa se inicia há aproximadamente $1,8 \mathrm{Ga}$ por um rifteamento continental (possivelmente decorrente de colapso de uma eventual cadeia transamazônica), acompanhado por magmatismo bimodal e sedimentação psamo-pelito-carbonática. $\mathrm{O}$ magmatismo se prolongou, na região, por mais 120 Ma e é caracterizado pela intrusão de granitos porfiríticos e sienogranitos. Posteriormente, uma série plutônica máfica datada de 900 Ma recorta esta sequência. O conjunto foi deformado e metamorfizado em regime compressivo/transpressivo durante o Ciclo Brasiliano (650 Ma).
Vários trabalhos contribuem para precisar aspectos geoquímicos das rochas magmáticas associadas ao desenvolvimento inicial da Faixa Orós. Dentre estes citam-se os de Sá (1991), McReath (1992), Figueiredo Filho \& Figueiredo (1992) e Sá et al (1995).

Parente (1995) estendeu e refinou a cartografia da porção leste-oeste da Faixa Orós, entre Orós e Aiuába. Uma análise detalhada dos aspectos sedimentares associados à individualização da Faixa Orós levou o autor a apresentar um modelo de evolução inicial desta faixa que, diferente do de Sá (1991), discorda, em particular, da ideia de riffeamento como processo tectônico que controlou a deposição da sequência metassedimentar da região.

Pouca atenção foi dada, nos trabalhos acima, aos terrenos que margeiam a Faixa de Orós, referidos por Sá (1991) como embasamentos leste e oeste. Os vários autores concordam com o fato de que estes embasamentos são diferentes. $\mathrm{O}$ de leste, que na concepção de Mendonça \& Braga (1987) separa as sequências de Orós e de Jaguaribe, é constituído por gnaisses bandados migmatíticos, com pequena contribuição paraderivada, recortados por rochas metaplutônicas félsicas (Sá 1991, Bezerra et al 1992, Parente 1995). O "embasamento oeste" é constituído sobretudo por rochas metassedimentares, principalmente pelíticas, de alto grau metamórfico (xistos com sillimanita e fusão parcial mais ou menos avançada) (Sá 1991, Parente 1995). Dados geocronológicos (método $\mathrm{Rb} / \mathrm{Sr}$ ) fornecem uma idade de 2,6 Ga (Sá et al 1988 e Macedo et al 1988) para os gnaisses bandados de leste, o que é compatível com as evidências de uma tectônica tangencial pré-brasiliana, ausente naFaixa Orós, nestas rochas (Bezerrae et al 1992). Na ausência de dados geocronológicos do "embasamento oeste", a maioria dos autores aceita o seu enquadramento no Grupo Ceará, mas apenas discordam quanto a idade, evolução mono ou policíclica, etc..., deste Grupo.

QUADRO GEOLÓGICO A concentração progressiva dos trabalhos na Faixa Orós levou a uma perda de visão de conjunto, mascarando o fato de que ela pertence a umaunidade geotectônica maior para a qual sugerimos o nome de Sistema Orós-Jaguaribe.

O Sistema Orós-Jaguaribe é representado, no Ceará, por um cinturão sigmoidal de aproximadamente $500 \mathrm{~km}$ de extensão longitudinal e sua largura, no Ceará, ultrapassa $75 \mathrm{~km}$ nas porções mais amplas (Fig. 2). No Oeste Africano, Caby \& Andreopoulos-Renaud (1983) descrevem conjuntos litológicos semelhantes em constituição e idade (a "Série dos Quartzitos do Proterozóico Terminal Inferior"). Eles se estendem longitudinalmente, de modo mais ou menos contínuo, por quase $2.000 \mathrm{~km}$. Parte destes conjuntos pode representar a continuação natural do Sistema Orós-Jaguaribe na África.

O sigmóide apresenta duas principais virgações: a de Icó, marcada por uma inflexão do Sistema que passa de ENEWS W a oeste para NNE-SSW e a de Banabuiú que caracteriza uma inflexão de NNE-SSW para NE-SW.

Este sistema é constituído, de maneira simplificada, por duas faixas metavulcano-sedimentares associadas à ortognaisses, geralmente porfiríticos, sub-alcalinos a alcalinos (as sequências Orós e Jaguaribe de Mendonça \& Braga 1987), separadas por um embasamento (o "embasamento leste" de Sá 1991) que pode ser subdividido em dois blocos, o bloco Jaguaretama na porção NS e o bloco São Nicolau na porção EW. 


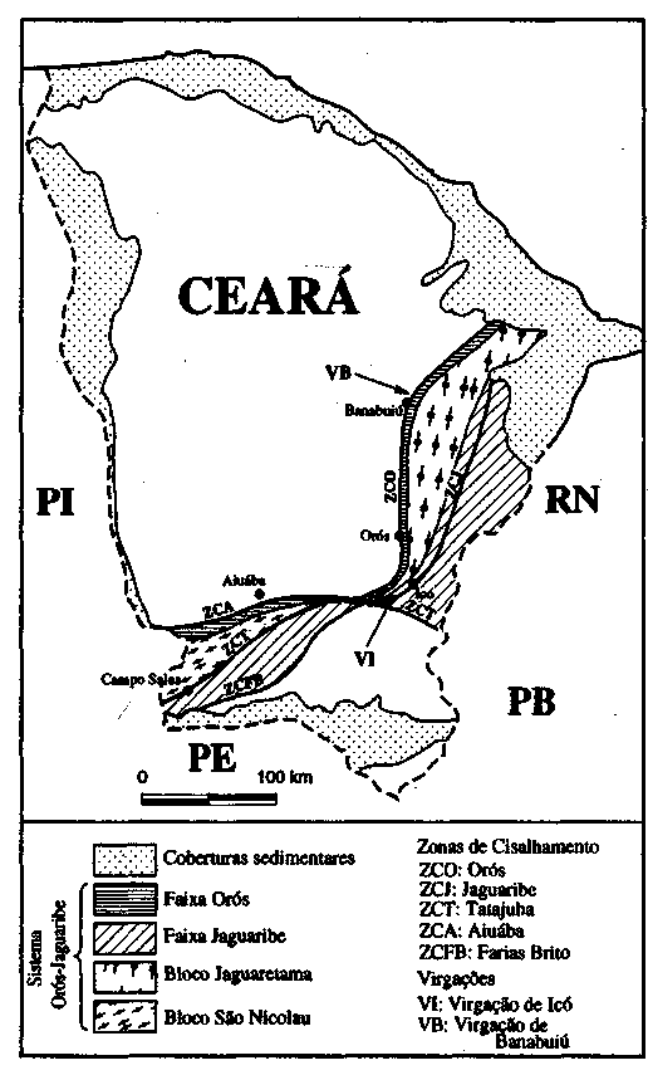

Figura 2 - O Sistema Orós-Jaguaribe no Ceará Figure 2 - The Orós-Jaguaribe System in Ceará

As faixas supracrustais e os ortognaisses porfiríticos associados (Granitos Lima Campos), que marcam as bordas do Sistema, receberam, na sua porção NNE-SSW, a denominação de Faixa Orós e Faixa Jaguaribe, mas podem ser seguidas, de modo contínuo, na porção ENE-WSW do Sistema, até as regiões de Aiuába (Faixa Orós) e de Campo Sales (Faixa Jaguaribe). Mais a oeste, a Faixa Orós está encoberta por rochas sedimentares da Bacia do Parnaiba, enquanto a Faixa Jaguaribe prolonga-se no Piauí pela região de Fronteiras, onde está coberta por rochas sedimentares fanerozóicas da Bacia do Parnaiba.

A Faixa Vulcano-Sedimentar Orós é geralmente estreita, pois a sua largura varia entre 2 e $13 \mathrm{~km}$, com a máxima na região de Orós-Lima Campos. Já a Faixa Vulcano-Sedimentar Jaguaribe apresenta uma largura maior e, embora sua cartografia não esteja estabelecida de maneira definitiva, é provável que deva ultrapassar, em certos pontos, $50 \mathrm{~km}$.

O embasamento, que representa a parte central do Sistema, está quase ausente na sua parte mais estreita, que corresponde à virgação de Icó. Tanto a porção NNE-SSW como a porção ENE-WSW apresentam largura igual ou superior a $35 \mathrm{~km}$.

Os limites do Sistema no Ceará são relativamente bem definidos:

- A porção ENE-WSW da Faixa Orós está separada do embasamento situado a norte pela Zona de Cisalhamento de Aiuába. Esta zona de Cisalhamento materializa uma brutal mudança de ambiente tectono-metamórfico. A tectônica transcorrente e o metamorfismo de fácies xisto verde da Faixa de Orós contrastam com a tectônica tangencial e metamorfismo de fácies anfíbolito alto do embasamento.
- A porção NNE-SSW desta faixa, também separada do embasamento situado a oeste por uma discordância tectonometamórfica, bem marcada na região de Orós, onde a faixa homónima apresenta uma tectônica transcorrente e um metamorfismo de fácies anfíbolito baixo, menos marcada a partir da virgação situada a norte de Banabuiú, onde o metamorfismo da Faixa Orós atinge condições de fácies anfíbolito alto a granulito (Caby et al. 1995). Esta discordância tectonometamórfica corresponde, segundo a maioria dos autores, a uma zona de Cisalhamento dúctil, a Zona de Cisalhamento de Orós, mas trabalhos detalhados em várias partes desta discordância não confirmam totalmente esta interpretação.

- A porção ENE-WSW da Faixa Jaguaribe, limitada a sul pela Zona de Cisalhamento de Farias Brito, que se junta, na região de Orós, à Zona de Cisalhamento de Tatajuba. Os terrenos situados imediatamente a sul destes acidentes são interpretados como arqueanos ou paleoproterozóicos que provavelmente evoluíram de modo policíclico (Unidade Granjeiro, nome informal utilizado por Vasconcelos \& Gomes -CPRM, comunicação pessoal).

- O limite leste tradicional da Faixa Jaguaribe, na sua porção NNE-SSW, é a Zona de Cisalhamento Jaguaribe. Entretanto, vários argumentos sugerem outro limite desta faixa. É impossível, no campo, individualizar a Zona de Cisalhamento, pois o que foi cartografado como tal é a encosta dos granitos da Serra do Pereiro, uma feição geomorfológica controlada por falhas mais recentes. Observa-se uma sucessão de faixas de deformação intensa, de regime transcorrente, alternadas com faixas de deformação mais branda. Também é possível mostrar uma passagem contínua entre os Granitos Lima Campos da região de Orós e os da Serra do Pereiro, geralmente considerados como tardi-brasilianos (ver p. ex. Cavalcante et al. 1983). Esta passagem é observada, por exemplo, a sudeste da cidade de Icó. Em vista disto, incluímos estes granitos provisoriamente na nossa definição da Faixa Jaguaribe. Estudos geocronológicos e geoquímicos estão em curso para melhor enquadrar estratigraficamente estas rochas. É também notável a semelhança entre as Faixas Jaguaribe e Orós e uma faixa de rochas supracrustais monocíclicas descritas por Jardim de Sá et al. (1986), localizadas no extremo oeste do Rio Grande do Norte. Neste trabalho, os autores já sugerem a semelhança entre as metaplutônicas associadas às supracrustais e aos ortognaisses descritos por Caby \& Andreopoulos-Renaud (1983) no Hoggar. Jardim de Sá (1994) opta por uma possível correlação entre estas supracrustais (Grupo Serra de São José) e o "Grupo Orós". Por continuidade, parece natural também incluir as supracrustais e os ortognaisses associados na Faixa Jaguaribe do Sistema Orós-Jaguaribe que, nesta nova definição, estender-se-a pelo Rio Grande do Norte, margeada por um embasamento gnáissico-migmatítico de idade provável arqueana ou paleo-proterozóica. O limite do Sistema estaria marcado, nesta região, por zonas de Cisalhamento dúctil (Sá 1994). Esta definição do limite leste da faixa poderá vir a ser modificada por trabalhos inéditos, em andamento (C. Magini).

LITOESTRATIGRAFIA Do ponto de vista litoestratigráfico, pode-se regionalmente distinguir (Figs. 2, 3 e 4):

- O Sistema Orós-Jaguaribe, representado pelas Faixas Orós e Jaguaribe separadas por um embasamento representado pelos blocos Jaguaretama e São Nicolau;

- As encaixantes deste Sistema: o Ceará Central a norte da Zona de Cisalhamento de Aiuába e a oeste da zona de Cisa- 
lhamento (?) de Orós (Caby \& Arthaud 1986, Caby et al. 1991); a Unidade Granjeiro a Sul das Zonas de Cisalhamento de Farias Brito e Tatajuba, e um complexo gnáissico migmatítico possivelmente no Rio Grande do Norte, a Leste do Grupo Serra de São José e separado do Sistema por zonas de cisalhamento;

- Uma cobertura sedimentar mesozóica representada pela sequência elástica imatura das bacias de Iguatu, Malhada Vermelha e Lima Campos, composta sobretudo por conglomerados polimíticos, arenitos arcoseanos e folhelhos depositados em um gráben ou meio-graben, e

- Os diques básicos, não deformados e não metamorfizados, pós-tectônicos e de idade mesozóica, os quais intrudem todas as unidades litoestratigráficas precedentes.

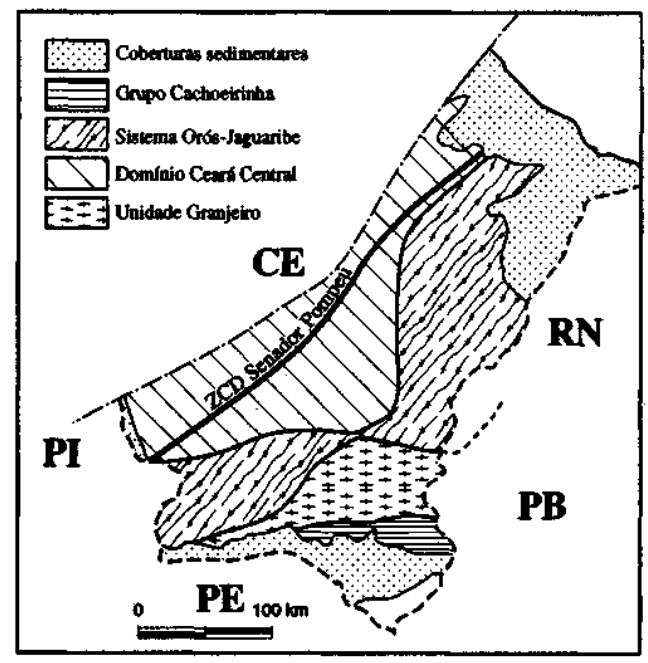

Figura 3 - O Sistema Orós-Jaguaribe e as unidades encaixantes

Figure 3 - The Orós-Jaguaribe System and its country-rocks
As duas últimas unidades não serão analisadas neste trabalho.

O Embasamento a oeste do sistema $O C E A R A$ CENTRAL Este domínio se extende por aproximadamente $80.000 \mathrm{~km}^{2}$ e está limitado a sul pela Zona de Cisalhamento de Aiuába, a leste pela porção N-S da Faixa de Orós, a norte pelas rochas sedimentares do Grupo Barreiras, a noroestepela Zona de Cisalhamento de Sobral-Pedro II e a oeste pelas rochas sedimentares da Bacia do Parnaíba (Fig. 3).

Apesar da cartografia ainda incipiente, escassez de dados geocronológicos e complexidade do arcabouço geológico, alguns traços fundamentais do Ceará Central podem ser destacados. Trata-se de um imenso domínio onde se associam foliações e metamorfismo de alto grau, geralmente anfibolito alto com migmatização mais ou menos avançada, testemunhos de um substancial espessamento crustal acompanhado de uma tectônica de nappe (Caby \& Arthaud 1986, Caby et al. 1991). As foliações planas são regionalmente perturbadas por mega-transcorrências dúcteis marcadas por largas faixas de milonitos e ultramilonitos (Vauchez et al. 1995). Dois tipos básicos de associações litológicas foram reconhecidos: sequências supracrustais essencialmente paraderivadas, principalmente pelíticas (Sequências de Independência, Quixeramobim, Canindé, Cariré, etc...) e associações do tipo TTG eventualmente associadas a supracrustais do tipo greenstone belt. Embora de modo polémico, devido à insuficiência de dados geocronológicos, as sequências metassedimentares foram consideradas como frutos de uma história termo-tectônica monocíclica brasiliana e agrupadas sob a denominação de Grupo Ceará, enquanto que as demais associações são consideradas como arqueanas ou paleo-proterozóicas (ver discussão em Caby et al. 1995). Dados geocronológicos recentes (Brito Neves et al. 1995, Fetter et al 1995, Van Schmus et al. 1995a e 1995b) deixam antever um quadro geodinâmico complexo da evolução da Província Borborema, embora não

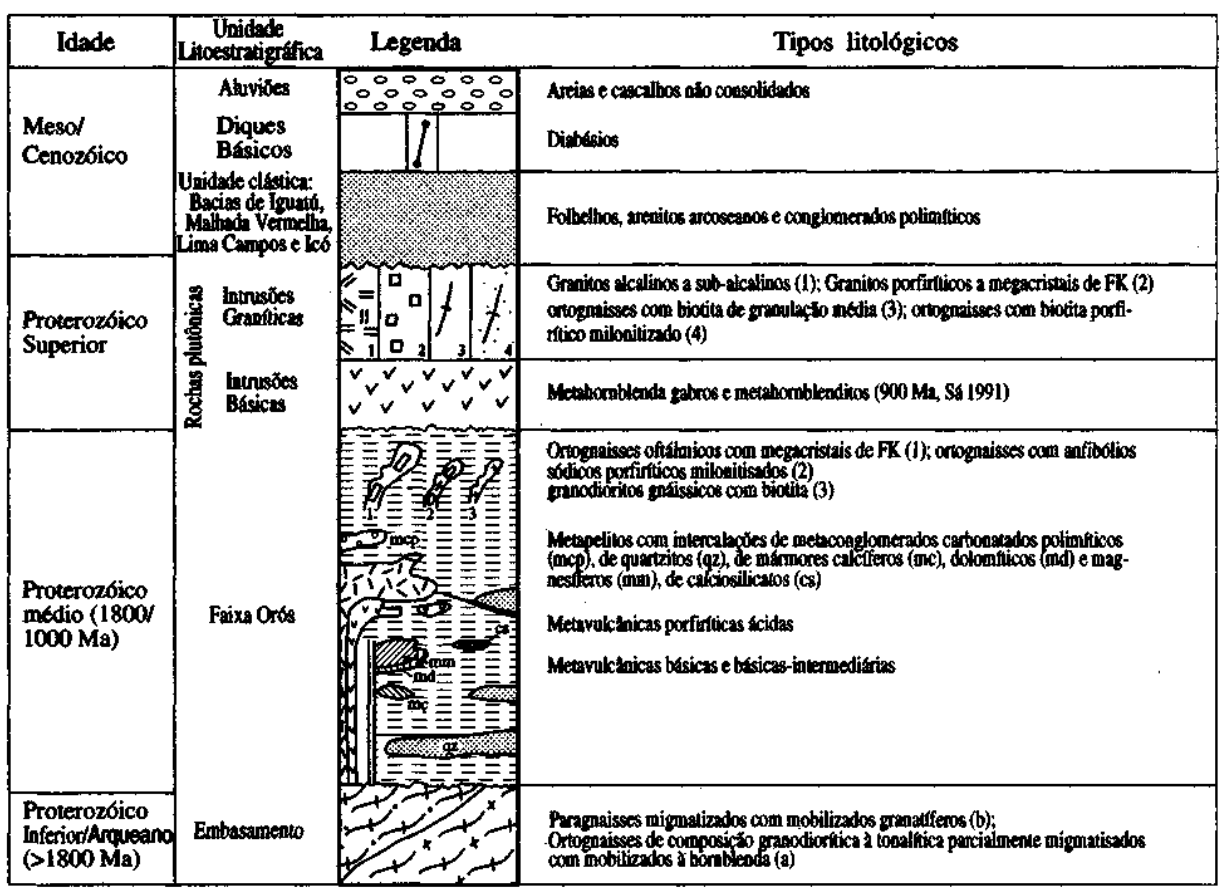

Figura 4 - Coluna litoestratigráfica da Faixa Orós (segundo Parente 1995)

Figure 4 - Lithoestratigraphic column of the Orós Belt (according to Parente 1995) 
modificando de maneira drástica o panorama do Ceará Central.

UNIDADE GRANJEIRO Corresponde a uma faixa estreita, com cerca de $60 \mathrm{~km}$ na sua parte mais larga, situada a sul de Icó, e estreitando para oeste, onde está parcialmente encoberta pelas rochas sedimentares da Bacia do Araripe (Figura 3). A norte, é limitada pelas Zonas de Cisalhamento Dúctil de Farias Brito e Tatajuba e, a sul, pelo Lineamento Patos, localmente referido como Falha de Iara (Cavalcante et al. 1983).

Esta unidade é constituída por duas sequências do tipo TTG, as Sequências de Cedro e de Aurora, situadas nas bordas $\mathrm{N}$ e $\mathrm{S}$ da unidade, ao longo das ZCD que a limitam, e separadas por uma sequência supracrustal (Sequência de Arrojado) mineralizada em talco e amianto (Cavalcante et al. 1983, Caby et al. 1991).

Estas sequências, de evolução policíclica, são cobertas por discordância, a sul de Cedro, por uma unidade contendo na base quartzitos conglomeráticos que dão lugar, para o topo, a metapelitos com biotita-andalusita-estaurolita-sillimanita (fibrolita), e informalmente denominada de Formação Quartzítica de Lavras da Mangabeira por Caby et al. (1995). Esta unidade encerra uma história tectono-termal monocíclica brasiliana (Monié et al. no prelo).

O Embasamento interno O embasamento, subdividido nos Blocos Jaguaretamae São Nicolau, é parte integrante do Sistema Orós-Jaguaribe, visto ser possível demonstrar, pelas relações de intrusão dos Ortognaisses Lima Campos, que ele é a infraestrutura direta das Faixas Orós e Jaguaribe e não o resultado de uma colagem tectônica ao longo de zonas de cisalhamento dúctil. Apesar das marcantes semelhanças entre os dois blocos, também existem algumas diferenças. O Bloco Jaguaretama é caracterizado por Ortognaisses tonalíticos contendo mobilizados trondhjemíticos, Ortognaisses graníticos, ambos geralmente bandados e parcialmente migmatizados, e rochas metassedimentares, geralmente pelíticas, com biotitagranada-sillimanita e frequentemente migmatizados, com raros quartzitos e rochas calcissilicáticas. Ao contrário do que é geralmente aceito na literatura, a unidade paraderi vada é uma parte importante do Bloco Jaguaretama. Ela representa provavelmente uma cobertura da sequência TTG e sua história tectono-termal registra uma tectônica policíclica. Já no Bloco São Nicolau, as rochas metassedimentares são raras ou ausentes.

A Faixa Orós ROCHAS METASSEDIMENTARES São sobretudo metapelitos representados em particular por xistos aluminosos com intercalações de quartzitos, mármores calcíticos, dolomíticos e magnesianos, rochas calcissilicáticas e quartzitos carbonosos.

Do ponto de vista petrográfico, os xistos podem ser classificados como xistos à clorita, xistos aluminosos ricos em andalusita, xistos negros aluminosos com granada, estaurolita e andalusita, xistos a duas micas, xistos a duas micas e granada e xistos feldspáticos ou metagrauvacas. Os xistos aluminosos com andalusita e os xistos negros aluminosos com granada, estaurolita e andalusita se localizam no setor centro-este, próximo à base da sequência, enquanto os demais estão localizados na porção superior.

Os quartzitos sustentam os principais acidentes topográficos e ocorrem intercalados nos xistos de duas maneiras: (a) como corpos contínuos de espessura decamétrica e extensão quilométrica, como os que sustentam as Serras de Orós e do Franco e (b) como lentes de espessura e comprimento decamétricos, distribuídos em toda a sequência metapelítica.

Sua distribuição é heterogénea. Eles são bastante abundantes no nordeste da Faixa e diminuem progresivamente em extensão e em volume em direção ao extremo sudoeste. É o inverso da distribuição da sequência carbonática, muito abundante e mais cálcica no extremo sudoeste (região de Pio IX e Aiuába), mas que diminui em extensão e volume, torna-se mais magnesiana para $\mathrm{NE}$, atingindo o pico da diferenciação na região de Alencar-Orós. Tais relações sugerem uma deposição sob condições mistas parálico-deltáicas.

A composição dos quartzitos é variável. Ora são lentes de quatzito conglomerático oligomítico em meios a metaritmitos, ora são quartzitos quase puros, quartzitos micáceos com turmalina, quartzitos com sillimanita ou, ainda, quartzitos carbonosos com até $2 \%$ de matéria orgânica. A matéria orgânica deve ser de ambiente marinho, mais precisamente parálico.

As rochas calcissilicáticas e carbonáticas formam um rosário de lentes que se estende por mais de $100 \mathrm{~km}$ segundo a direção, localizadas sobretudo na porção intermediária da sequência metapelítica. Sua composição varia entre rochas calcissilicáticas com diopsídio, metaconglomerados carbonatados, mármores calcíticos quase puros, mármores dolomíticos com escapolita, brechas de dissolução com lutecita e nódulos de sulfato pseudomorfizados por quartzo fibrorradiado, metadolomitos petalóides e magnesititos. Isto indica que grande parte dessas rochas evoluíram em um ambiente marinho evaporítico.

A sucessão litoestratigráfica do domínio da Faixa Orós consiste de xistos aluminosos mais ou menos negros localizados na porção basal, seguidos da associação carbonada na porção intermediária e os xistos com duas micas e feldspáticos na superior.

ROCHAS METAVULCÂNICAS São representadas sobretudo por rochas félsicas, com rochas vulcânicas e hipoabissais máficas subordinadas. As rochas félsicas, embora ocorram em diferentes níveis na sequência metapelítica, são mais frequentes em associação com rochas hipoabissais e Ortognaisses facoidais intrusivos nos metapelitos e no embasamento sul e sudeste.

As rochas metavulcânicas variam, petrograficamente, de composição entre dacitos, riodacitos e riólitos com fenocristais de feldspato e quartzo. Nos metariólitos e metatufos félsicos, o quartzo é frequentemente azulado. Dados geoquímicos obtidos por Sá (1991), McReath (1992) e Sá et al. (1995) indicam que a maioria destas rochas são de natureza alcalina à subalcalina de ambiente continental. Dados geocronológicos U-Pb de zircão e $\mathrm{Rb}-\mathrm{Sr}$ e Sm-Nd em rocha total destas rochas vulcânicas revelaram idade aproximada de $1.800 \mathrm{Ma}$ (Sá 1991).

As rochas vulcânicas máficas e/ou básico-intermediárias são representadas por xistos com clorita, metabasaltos e metandesitos, em geral associados e/ou recortados por rochas máficas a ultramáficas hipoabissais. Estas últimas também intrudem as rochas carbonáticas magnesianas e afloram sobretudo entre Alencar, Santarém e Pitombeiras, por uma extensão superior a $25 \mathrm{~km}$. Todavia, podem ser encontradas também no leito do Rio Jaguaribe, próximo à Barragem de Orós, onde são representadas pelos metabasaltos e/ou metandesitos de níveis estratigráficos inferiores de uma sucessão de 
rochas efusivas e hipoabissais félsicas. A passagem das rochas máficas e intermediárias para as félsicas é brusca, localmente progressiva entre os termos intermediários e félsicos, sublinhando uma estratificação vulcânica. Estes contatos sugerem, seja um magmatismo bimodal máfico a félsico, seja a formação de alguns níveis félsicos por cristalização fracionada.

Do ponto de vista geoquímico, Sá (1991), McReath (1992) e Sá et al. (1995), definiram dois grupos distintos de rochas máficas. Um está localizado na região de Alencar e adjacências (basalto Alencar de Sá et al. 1995), cujo comportamento geoquímico seria similar aos basal tos tipo EMORB, empobrecidos em LILE e LREE. Outro do tipo transalcalino, enriquecido em LILE e LREE e empobrecido em HFSE, localizado na porção este desta faixa. Para estes autores,-estas variações são atribuídas à influência da fonte magmática à época de sua formação ao final do Ciclo Transamazônico ( 1.8Ga). Ainda de acordo com estes autores, estas rochas representariam as primeiras manifestações magmáticas ocorridas no domínio desta faixa, enquanto os metariólitos, com idade em torno $1780 \mathrm{Ma}$, teriam ocorrido quase imediatamente. Entretanto, observa-se, no campo, que a maior parte das rochas máficas da região de Alencar e adjacências são intrusivas nas rochas carbonáticas magnesianas. Isto sugere que as rochas carbonáticas são mais antigas que $1.8 \mathrm{Ga}$ e que as vulcânicas são mais jovens. Neste último caso, poderia-se correlacionar estas rochas à associação plutônica máfico-ultramáfica de $900 \mathrm{Ma}$ situada a oeste de Santarém. Assim, as interpretações acerca das unidades máficas de Alencar deveriam ser reavaliadas à luz dos dados de campo, visto que elas podem ser muito mais jovem que comumente aceito.

ROCHAS METAPLUTÔNICAS Elas recortam o conjunto vulcano-sedimentar e vários tipos podem ser identificados: - Ortognaisses facoidais tipo Lima Campos, de composição granítica, textura porfirítica, com variedades locais que lembram a textura rapakivi. Estas rochas constituem o principal tipo plutônico da Faixa Orós, ou mesmo do Sistema OrósJaguaribeano, ocorrem lâminas ou sills quilométricos em meio a rochas vulcano-sedimentares e no embasamento arqueano e/ou proterozóico dos setores E-W e N-S da Faixa e sua idade U/Pb é da ordem de 1.700 Ma (Sá 1991);

- Ortognaisses com hornblenda e/ou biotita, de composição granodiorítica, localizados entre as vilas de Oros e Lima Campos;

- Ortognaisses com biotita, de composição granodiorítica, localizados entre e recortando o embasamento paraderivado e a sequência vulcano-sedimentar no setor centro-norte;

- Ortognaisses porfiríticos milonitizados, tipo Cariús, cujas características petrográficas e estruturais são comparáveis com os Ortognaisses facoidais acima descritos e que poderiam estar relacionados ao mesmo evento magmático.

Além dessas intrusões, algumas datadas e outras consideradas como do Mesoproterozóico, também ocorrem intrusões que, em virtude de seus aspectos composicionais e estruturais, são consideradas do Neoproterozóico. Dentre estas citam-se o biotita granito-gnáisse de Jucás, os granitos alcalinos ou sub-alcalinos da região de Saboeiro e da Serra do Morais e o Complexo Básico-Ultrabásico de Santarém, cuja idade $\mathrm{Sm} / \mathrm{Nd}$ em rocha total é de $880 \mathrm{Ma}$ (Sá 1991).

A Faixa Jaguaribe Nesta faixa, verifica-se, sem o detalhe da Faixa Orós, uma nítida predominância da associação vulcano-plutônica sobre os metassedimentos. Os metassedimentos, representados sobretudo por xistos e quartzitos, ge- ralmente ocorrem como lentes de espessura reduzida e comprimento decamétrico associadas às lavas e tufos félsicos, sustentando pequenas elevações na região.

Os quartzitos são em geral finos, quase puros ou com moscovita, enquanto os xistos contêm moscovita, biotita e granada. $\mathrm{O}$ conjunto está recortado por espessas lâminas ou batólitos de Ortognaisses facoidais similares aos do tipo Lima Campos, acima descritos.

As rochas carbonáticas são muito menos abundantes nesta faixa, distribuindo-se num domínio estreito e alongado acima da Zona de Cisalhamento de Farias Brito nas regiões próximas à cidade homónima e de Umari, a SE de Icó, podendo estes últimos pertencerem à Unidade Granjeiro e não ao Sistema. Isso indica que a sedimentação na faixa Jaguaribe foi dominantemente psamo-pelítica e, provavelmente, de ambiente continental e, por conseguinte, diferente da Faixa Orós, de ambiente misto marinho parálico-deltáico.

As rochas vulcânicas, por sua vez, são representadas sobretudo por lavas e piroclásticas ácidas. Sua composição é dominantemente riolítica e encontram-se em geral associadas e/ou recortadas pelos Ortognaisses facoidais.

Além dos Ortognaisses facoidais característicos, as rochas plutônicas são, ainda, representadas por diques de diorito, de possança métrica a decamétrica, intrudidos nos gnaisses. Os granitos que sustentam a Serra do Pereiro apresentam a mesma composição mineral e texturas semelhantes às dos ortognaisses facoidais Lima Campos, encontrando-se em associação com lavas e tufos félsicos. Isso pode ser observado no perfil BR116-Pereiro, onde aflora, próximo à encosta, uma associação de lavas e tufos ácidos intercalados com xistos e quartzitos, o que demonstra a íntima associação das rochas graníticas com as lavas e piroclásticas. Assim, é provável que os granitos Pereiros considerados comumente como do NeoProterozóico e relacionados ao Ciclo Brasiliano (Cavalcante et al. 1983, Jardim de Sá 1984, Mendonça \& Braga 1987) sejam correlacionados aos granitos tipo Lima Campos. Entretanto, são necessários estudos geoquímicos e geocronológicos para melhor conhecer.e correlacionar estas rochas.

DEFORMAÇÃO Foram descritas, para cada segmento estudado do Sistema Orós-Jaguaribe, sequências deformacionais complexas (Mendonça \& Braga 1987, Sá 1991, Parente 1995), polifásicas (policíclicas no caso de Bezerra et al. 1992). Esta aparente complexidade, fruto da heterogeneidade natural da deformação, mascara uma realidade relativamente simples.

Estruturalmente, dois comportamentos contrastantes podem ser descritos:

- As Faixas Orós e Jaguaribe exibem uma foliação de alto ângulo, sub-vertical na porção N-S do Sistema e com mergulhos superiores a $45^{\circ}$ (geralmente para Sul) na sua porção E-W. As lineações de estiramento são geralmente sub-horizontais. As faixas apresentam um background deformacional intenso e zonas de cisalhamento marcadas por faixas de milonitos e ultramilonitos, paralelas à foliação das faixas, afetando mais as porções ortoderivadas, mas podem também estar presentes nos metassedimentos.

Este quadro geral evidencia, como admitido pelos diversos autores, que estas faixas se comportaram com cinturões transcorrentes (o sentido dextral destas transcorrências é também universalmente aceito), onde a deformação está distribuída de maneira extremamente heterogénea (Sá 1991, Jardim de Sá 1994, Parente 1995). Além da variação de intensidade, observam-se variações do tipo de deformação, o qual passa, 
dependendo da região, do campo da deformação plana ou achatamento para o da constrição, como na região de Lima Campos, ou mesmo de mecanismo, como mostram Sá (1991) e Sá \& Bertrand (1992) que parte da deformação foi por cisalhamento puro, ern regime transpressional.

A análise da foliação regional nas duas faixas, sobretudo nas rochas ortoderivadas, mostra que ela não está superimposta a uma foliação de baixo ângulo que poderia caracterizar uma tectônica tangencial pretérita.

Fica, portanto, perfeitamente estabelecido para as duas faixas metavulcano-sedimentares, o caráter monocíclico da deformação e a unicidade do regime transcorrente dextral.

Uma diferença notável de comportamento pode ser observada entre as porções NS e EW do Sistema. Na primeira, o background deformacional é mais intenso, mas as zonas de cisalhamento dúcteis $s S$. são raras. $\mathrm{Na}$ segunda, domínios menos deformados são frequentes, largas zonas de milonitosultramilonitos são comuns e o caráter não coaxial da deformação é mais acentuado.

- As porções de embasamento inclusas no Sistema apresentam um comportamento muito diferente das duas faixas marginais. Na porção N-S (Bloco Jaguaretama), o embasamento geralmente apresenta uma foliação ondulada, com mergulhos médios inferiores a $45^{\circ}$, o que caracteriza uma tectônica tangencial (Bezerra et al. 1992). A tectônica transcorrente deixou, nestas rochas, um registro limitado às zonas de contato com as Faixas Orós e Jaguaribe. É sempre claro que a tectônica transcorrente é posterior à tectônica tangencial. Já no embasamento localizado a E-W do sistema (Bloco São Nicolau), a tectônica transcorrente foi mais intensa, provocando uma transposição mais ou menos completa da(s) foliação(ões) anterior(es), ainda caracterizadas localmente por mobilizados e um bandamento migmatítico, contrastando fortemente com o baixo grau metamórfico das rochas supracrustais e gnaisses porfiríticos associados. Estas observações evidenciam o caráter policíclico da deformação do embasamento, contrastando com o monociclismo das faixas marginais.

METAMORFISMO Como no caso da deformação, o metamorfismo, complexo no detalhe (Sá 1991, Parente 1995), apresenta uma certa simplicidade quando tratado na escala do Sistema. Novamente é necessário considerar uma notável diferença entre as histórias do embasamento interno e das faixas.

Tanto na porção N-S como na E-W, o embasamento foi afetado por um metamorfismo de fácies anfibolito alto caracterizado por uma incipiente a acentuada migmatização dos diversos litotipos e pela presença de sillimanita nos metapelitos da porção N-S. Já os metassedimentos da Faixa Orós, melhor estudados do que os da Faixa Jaguaribe, mostram uma mudança progressiva, ao longo da faixa, de um metamorfismo de fácies xisto verde no extremo oeste, para fácies anfibolito baixo na região de Alencar/Orós/Cangati, caracterizado pela presença de estaurolita e andalusita. A NE da virgação de Banabuiú, região do Boqueirão do Cesário, os quartzitos apresentam sillimanita e os metapelitos associados metamorfismo na fácies granulito (Caby et al.1995), do tipo baixa pressão com uma característica singular. Na região da virgação de Icó, a associação biotita 2 , estaurolita, granada e andalusita formou-se por recristalização estática sobre uma foliação fina com mica branca e biotita 1 , o que pode indicar um espessamento crustal limitado (a pressão determinada por Sá 1991 não ultrapassa $3 \mathrm{~kb}$ ), mas rápido, o reequilíbrio térmico se processando parcialmente após a interrupção, ao nível regional ou local, da deformação (uma pequena rotação da foliação interna da biotita 2 e estaurolita evidencia incrementos deformacionais limitados durante o seu crescimento). $\mathrm{O}$ aumento do grau metamórfico de oeste para leste foi provavelmente associado ao próprio estilo da deformação, mais transcorrente na porção E-W do Sistema, com espessamento limitado, mais transpressional na porção NS, com espessamento máximo a NE da virgação de Banabuiú. Os dados geobarométricos preliminares indicam, segundo Caby et al. (1995), pressões da ordem de $6 \mathrm{~kb}$ nos xistos da região do Boqueirão do Cesário.

QUADRO GEOTECTÔNICO DO SISTEMA ORÓSJAGUARIBE Sedimentologia, magmatismo e a individualização inicial do Sistema Recentemente, Sá (1991) e Sá et al (1995) propuseram, a partir de dados geoquímicos das rochas ortoderivadas, que a associação vulcano-sedimentar-plutônica da Faixa Orós desenvolveu-se em um ambiente do tipo rift, com história marcada por diferentes fases de evolução. Segundo estes autores, a história inicia, há aproximadamente $1,8 \mathrm{Ga}$, com um rift continental, ou passivo no sentido de Sengor \& Burker (1978), possivelmente decorrente do colapso de uma eventual cadeia transamazônica. Tal fenómeno foi acompanhado por um magmatismo bimodal e uma sedimentação psamo-pelítica-carbonática. Os processos magmáticos se prolongam na região por mais $120 \mathrm{Ma}$, caracterizados por intrusões de granitos porfiríticos e sienogranitos. Posteriormente, um plutonismo máfíco, datado de $900 \mathrm{Ma}$, recortou esta sequência e o conjunto foi deformado e metamorfízado em regime compressivo-transcorrente no Ciclo Brasiliano (650 Ma).

As informações obtidas no domínio sedimentar levaram Parente (1995) e os autores deste trabalho a propor alternativas ao modelo de Sá $(1991,1995)$ e seguidores. Como se sabe, os depósitos sedimentares de ambiente de tipo rift, seja ativo ou passivo, consistem de sedimentos elásticos terrígenos imaturos, como arcóseos, quartzitos feldspáticos e conglomerados originados de fontes relativamente próximas (horsí), em regime de soerguimento rápido (Windley 1984, Condie 1989, Green 1992).

Na região estudada, particularmente na Faixa Orós, os metassedimentos são bastante diferenciados e caracterizados predominantemente por xistos aluminosos e quartzitos finos quase puros ou aluminosos. Os grandes depósitos de quartzitos indicam que eles podem ser: (a) oriundos de erosão ou reciclagem de arenitos mais antigos, com avançado grau de maturidade, ou (b) produtos de um só ciclo de erosão sobre uma área com maturidade pedológica e relevo aplainado, favorecidos por condições tectônicas estáveis. Em ambos os casos, as condições sobre o domínio continental eram suficientemente estáveis para permitir uma boa reciclagem ou seleção quase perfeita dos grãos de quartzo, sem considerar um possível ambiente praial ou litorâneo, incompatível com um ambiente de rift.

Assim, acredita-se que a formação da associação metapsamo-pelítica da região requereu um domínio continental estável sob influência de uma pedogênese pronunciada. Observa-se que, na época da deposição desses metassedimentos $(\sim 1.8 \mathrm{Ga})$, os continentes eram desprovidos de cobertura vegetal. Isso sugere que os fenómenos de alteração estavam mais relacionados a um domínio continental relativamente estável, submetido a intemperismo sob clima quente e úmido. 
Isso permitiu o desenvolvimento dos termos aluminosos por lixiviação de $\mathrm{Ca}$ e $\mathrm{Na}$.

Por outro lado, o modelo de uma bacia epi-plataformal subdivida em várias sub-bacias, como sugerido por Parente (1995), parece explicar melhor o ambiente de deposição da sequência sedimentar que aquele de rift proposto anteriormente por outros autores. Neste sentido, Parente (1995) reconheceu, na Faixa Orós, duas grandes depressões onde se depositaram tanto sedimentos detríticos continentais quanto carbonáticos. A maior e mais profunda seria a da região de Alencar-Orós, e onde os xistos aluminosos apresentam características de ritmitos e, assim, a fácies mais profunda, provavelmente progradante de um delta. Adicionalmente, os xistos negros e quartzitos carbonosos só ocorrem nesta região, indicando um ambiente confinado, de circulação restrita e condições redutoras localizadas preferencialmente próximo ao fundo. Isso é devido, em parte, às variações laterais de salinidade e, portanto, de densidade, capaz de induzir a estratificação de corpos d'água superpostos, favorecendo a anoxia do corpo d'água inferior (Guelorget \& Perthuisot 1983). Um tal fenómeno se manifesta sobretudo dentro de ambientes salinos e/ou quando se desenvolve uma zona de mistura entre água doce e água do mar, como em estuários, canais de deltas e mangues. Além disso, um tal sítio é favorável à produção e sedimentação de matéria orgânica, a qual é consumida por micro-organismos saprófitos que favorecem a anoxia do meio por sua respiração e, eventualmente, a produção de $\mathrm{H}_{2} \mathrm{~S}, \mathrm{CH}_{4}$ e $\mathrm{NH}_{4}$ (Guerlorget \& Perthuisot 1983).

Por outro lado, os dois tipos de sedimentação tem uma distribuição que, na região, é inversa. Assim, a importância dos detritos continentais diminui em direção a sudoeste, ao encontro dos mármores, mais magnesianos para leste. Deste modo, os canais seriam alimentados, em certos períodos, por detritos muito maturos (quartzitos finos e quase puros) originados de um continente arqueano estável localizado a SE e/ou NE. Em outras épocas se depositaram os sedimentos carbonáticos com traços evaporíticos. Estes evoluiriam ao pólo magnesiano através de diferenciação química, isto é, através da depuração do $\mathrm{Ca}$ precipitado sob forma de carbonatos cálcicos ou cálcico-magnesiano ou ainda de sulfates. Segundo Parente (1995), isto sugere uma bacia parálica aberta para S-SW. Os depósitos mais espessos de magnesita, localizados para ENE (região de Alencar) indicariam uma bacia mais desenvolvida e um ambiente mais confinado, o que corresponderia às relações observadas dentro de um sistema misto parálico-deltáico.

Em relação a Faixa Jaguaribe, as informações sobre a associação vulcano-sedimentar não são ainda conclusivas, de modo que um estudo mais pormenorizado se faz necessário para uma melhor compreensão da organização do conjunto vulcano-sedimentar. Todavia três fatos são notórios: (a) a diminuição da sequência carbonática magnesiana no interior desta faixa, particularmente, ao norte da cidade de Icó, (b) a pequena concentração de metassedimentos pelíticos nesta faixa comparativamente à abundância da associação vulcanoplutônica, e (c) o caráter dominantemente félsico e caráter alcalino a subalcalino, típico de regimes intracontinentais, da associação vulcano-plutônica.

Por outro lado, o posicionamento das rochas graníticas alcalinas ou subalcalinas é em geral associado ao caráter mais radioativo e adelgaçamento da crosta, sendo formada por ocasião da ascensão do material astenosférico, causado pela divergência de blocos continentais, e sua interação com a crosta inferior (ver, dentre outros, Black \& Liegeois 1993). Neste caso, o adelgaçamento crustal ou o caráter mais radioativo favoreceu a interação manto-crosta, permitindo a liberação da pressão da câmara magmática abaixo da litosfera rígida ocasionada por reativações de falhas litosféricas profundas. Tais falhas teriam tocado a crosta inferior ou mesmo o manto, favorecendo a ascensão e a diferenciação do magma granítico ao longo dessas estruturas.

A ocorrência de um menor volume de rochas máfico-ultramáficas e a maior quantidade de rochas vulcano-plutônicas félsicas alcalinas a sub-alcalinas na Faixa Jaguaribe indica que esta continha um substrato crustal mais espesso e que o seu adelgaçamento foi isuficiente para permitir a efusão ou ascensão de quantidade significativa de rochas máficas e/ou ultramáficas, como na Faixa Orós.

Assim, pode-se pensar que o começo da sedimentação marinha epicontinental no Sistema coincidiu com a fase de adelgaçamento crustal ou com a existência de uma crosta já afinada naquela época. É importante lembrar que este período correspondia ao fim do Paleoproterozóico e início do Mesoproterozóico, quando os fenómenos tectônicos eram ainda dúcteis, diferente daqueles do Fanerozóico. Neste caso, embora possa ter havido rift, o período de ri/hng representa somente o estágio final de uma prolongada fase extensional, precedido por uma sedimentação arenosa-pelito-carbonatada (QPC de Condiel989), característica de ambiente plataformal ou de bacias epi-plataformais.

A principal diferença entre este modelo e o de Sá (1991) e seguidores é que consideramos que o estágio evolutivo correspondente ao $\mathrm{n} /$ feamento e ascensão do magmatismo granítico ocorreu após a deposição da sequência sedimentar de um ambiente de plataforma ou de paraplataforma.

A Evolução Brasiliana do Sistema $O$ caráter monocíclico brasiliano da evolução termo-tectônica das Sequências Orós e Jaguaribe parece bem estabelecido, assim como o caráter basicamente transcorrente da deformação brasiliana. É possível admitir que as transcorrências se instalaram sobre porções afinadas de crosta continental.

O Sistema, de forma sigmoidal, mostra diferenças profundas no estilo da deformação a Oeste e a Norte da virgação de Icó. Há uma maior concentração da deformação em zonas de cisalhamento na parte E-W, inclusive nas bordas do Sistema, com uma não coaxialidade acentuada da foliação. Há, também, uma maior dificuldade para definir zonas de cisalhamento ss. na porção NS, onde a deformação, embora heterogénea, tende a ser mais espalhada, a não ser no caso do embasamento do Bloco Jaguaretama, que se comportou de maneira rígida durante o Ciclo Brasiliano. Estas diferenças de estilo deformacional podem ser paralelizadas com notáveis diferenças entre os níveis crustais, caracterizados pelas condições metamórficas, atualmente expostos nos dois segmentos onde o metamorfismo varia de fácies xisto verde a anfibolito baixo a oeste da virgação de Icó e de fácies anfibolito baixo a granulito a norte da mesma, indicando um espessamento crustal muito mais marcado.

Isto mostra que a quantidade de movimento ao longo do segmento EW da faixa deve ter sido maior do que a quantidade de movimento ao longo do segmento NS. Uma componente transpressional limitada explicaria o espessamento maior deste último (é difícil imaginar, para todo o segmento NS, uma foliação desenvolvida principalmente em regime coaxial com encurtamento $\mathrm{EW}$, alternando com estreitas faixas puramente 
transcorrentes, geradas em cisalhamento simples, como no modelo proposto por Sá \& Bertrand 1992 para a região de Orós).

Estas diferenças podem ser explicadas considerando que o segmento NS do Sistema, entre as virgações de Icó e Banabuiú, conserva a sua orientação inicial (não levando em conta possíveis rotações pós-brasilianas) enquanto que o segmento EW corresponde a um domínio arrastado no decorrer do funcionamento dos cisalhamentos EW da Zona Transversal.

Neste modelo, a deformação transcorrente do segmento NS seria essencialmente passiva, acompanhada de uma componente de encurtamento EW ligada ao funcionamento dos cisalhamentos transversais, enquanto que o segmento EW, reorientado e paralelizado às zonas de cisalhamento $\mathrm{EW}$, seria deformado em transcorrência pura e delaminado por zonas de cisalhamento internas.

A evolução précambriana do Sistema Orós-Jaguaribe está sintetizada na figura 5 .

CONCLUSÕES As unidades litológicas anteriormente denominadas Faixas Orós e Jaguaribe, que afloram na região Centro Sul do Ceará, representam, junto com porções' de embasamento, uma unidade geotectônica ímpar, com características próprias marcantes, o Sistema Orós-Jaguaribe.
Este Sistema iniciou sua individualização há cerca de 1,8 Ga quando um embasamento metamorfízado em condições de fácies anfibolito alto e marcado por uma deformação tangencial foi submetido a um estiramento resultando na individualização de domínios, provavelmente lineares, de crosta adelgaçada. $\mathrm{O}$ afinamento crustal foi acompanhado de uma sedimentação plataformal ou para-plataformal e de processos magmáticos intracratônicos de natureza alcalina a subalcalina.

Este Sistema preservou sua identidade durante o Ciclo Brasiliano, comportando-se como um corredor de trancorrência dextral. Ele não apresenta registro de tectônica tangencial, a não ser nas porções de embasamento interno, policíclico.

A geometria sigmoidal atual do Sistema e diferenças metamórficas e deformacionais entre as porções EW e NS mostram que estes segmentos apresentaram comportamentos diversos no decorrer da deformação: o primeiro é marcado por um regime transcorrente puro, associado a uma espessamento crustal limitado; o segundo associa uma transcorrência provavelmente passiva a um encurtamento responsável por um espessamento crustal maior.

Agradecimentos C.V.P agradece ao Grupo IBARVOTORANTIM e à CAPES pelo suporte financeiro de parte
Final do Proterozbico Inferior (?)

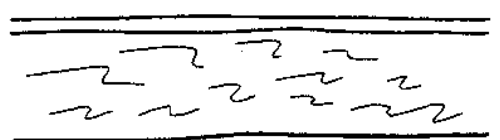

Início do Proterozóico médio (c.a. 1,8 Ga)

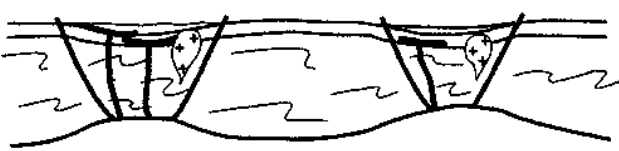

Rifteamento acompanhado de um extenso magmatisino alcalino
Estabelecimento de um ambiente plataformal sobre um embasamento já estruturado (deformação tangeacial, metamorfismo de fácies anfibolito alto)

\section{Proterozóico médio}

Magmatismo básico (c.a. $900 \mathrm{Ma}$ )

Final do proterozóico superior (Ciclo Brasiliano, 600 Ma)

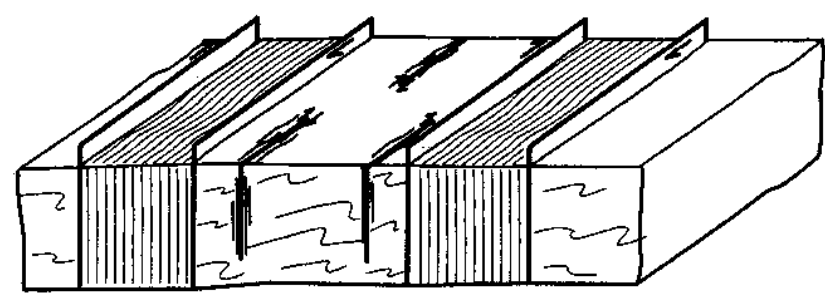

Deformaçăo em trans-

corréncia dextral e

metamorfismo dos

domínios afinados
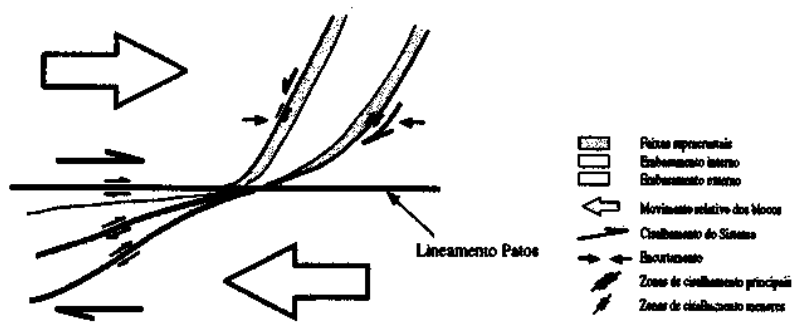

Ativação da Zona Transversal

Figura 5 - Evolução précambriana do Sistema Orós-Jaguaribe

Figure 5 - Precambrian evolution of the Orós-Jaguaribe System 
dos trabalhos de campo e ao Mr. JJ. Guillou pelos preciosos ensinamentos no domínio da paleogeografia. M.H.A. agradece ao CNPq pelo suporte financeiro de parte dos trabalhos de campo, à C.P.R.M. Fortaleza (Angelo, Thales, Maurílio, Prado, Zé Roberto e Paulo) pelas oportunidades de viagens de campo e pelas discussões proveitosas e, last but not least, ao Dr. R. Caby pelos seus ensinamentos. Enfim agradecemos o revisor (B. B. Brito Neves) cujos comentários ajudaram a melhorar este trabalho.

\section{REFERÊNCIAS}

ALMEIDA, F. F. M de.; HASUI, Y.; BRITO NEVES, B. B. \& FUCK, R.A 1977. Províncias estruturais brasileiras. In: VIII Simp. Geol. Nordeste. Campina Grande. Atas..., pg. 363-391.

BEZERRA, F.H.R.; FONSECA, V.P; AMARO, V.E. \& ACCIOLY, P.C.V. 1992. Evidências de uma tectônica tangencial na região do Médio Jaguaribe, Nordeste do Ceará: problemas e implicaçõ̃es. In: XXXVII Congr. BRAS. Geol. SBG/SP, São Paulo, Boi. Rés. Exp.. pg. 328-329.

BLACK, R. \& LIEGEOIS, J.P. 1993. Cratons, mobile belt, alkaline rocks and continental lithospheric mantle: the Pan-African testimony. /. Geol. Soe. London. 150: 89-98.

BRAGA, A.P.F. \& MENDONÇA, J.C.G.S. 1984. Sequências vulcano-sedimentares de Orós e Jaguaribe - Folha SB.24Z-A-1 - Região sudeste do estado do Ceará. In: XXXIII Congr. BRAS. Geol., Rio de Janeiro, SBG. Anais..., 5:2512-2526.

BRITO NEVES, B.B. 1975. Regionalização geotectônica do Precambriano nordestino. Tese de doutorado, USP, São Paulo. 198 p (Inéd.).

BRITO NEVES, B.B. 1983.0 mapa geológico do Nordeste oriental do Brasil, escala 1/1000000. Tese de Livre docência USP, São Paulo. 177 p. (Inéd.).

BRITO NEVES, B.B.; VAN SCHMUS, W.R.; HACKSPACHER, P.C. \& SANTOS, E.J. 1995. Geocronologia da Borborema, 1995: os fatos e as questões abertas. In: XVI Simp. Geol. Nordeste. Workshop Província Borborema, Recife, Atas..., no 14,2:410-413.

CABY, R. \& ANDREOPOULOS-RENAUD, U. 1983. Age à $1800 \mathrm{Ma} \mathrm{du}$ magmatisme subalcalin associe aux métasédiments monocycliques dans Ia chaine Pan-Africaine du Nord du Sanara Central. / African Earth Sc. 1(3/4): 193-197.

CABY, R.; SIAL, A.N.; ARTHAUD, M. \& VAUCHEZ, A. 1991. Crustal evolution and the Brasiliano Orogeny in Northeast Brazil. In: R. Dallmeyer \& P. Lecorché (eds.), Springer-Verlag. p 373-397.

CABY, R. \& ARTHAUD, M.H. 1986. Major Precambrian nappes of the Brazilian belt, Ceará, Northeast Brazil. Geology, 14:871-874.

CABY, R.; ARTHAUD, M. H. \& ARCHANJO, C.H. 1995. Lithostratigraphy and petrostructural characterization of supracrustal units in the Brasiliano Belt of Northeast Brazil: geodynamic implications. /. South Amer. Earth Sc. 8(3/4):235-246.

CAVALCANTE J. C.; FERREIRA C.A.; ARMESTO R.C.G.; MEDEIROS M.F.; RAMALHO R.; BRAUN 0. P. G,; BAPTISTA M. B. \& SILVA CUNHA de, H. C. 1983. Mapa Geológico do Estado do Ceará, Escala 1: 500.000. MME/DNPM/CPRM.

CONDIE, K.C. 1989. Plate Tectonics e Crustal Evolution. Pergamon Press, $467 \mathrm{p}$.

FETTER, A.H.; SANTOS, T.J.S.; NOGUEIRA NETO, J.A. \& VAN SCHMUS, W.R. 1992. Geocronologia U/Pb em zircão e Sm/Nd em rocha total do estado do Ceará -Resultados parciais. In: XVI Simp. Geol. Nordeste. WorkShop Província Borborema. Recife. Atas... No 14 , 2:418-422.

FIGUEIREDO FILHO, O.A. \& FIGUEIREDO, M.C.H. 1992. Litogeoquímica e evolução da faixa Jaguaríbeana -Ceará. In: XXXVII Congr. BRAS. Geol. SBG/SP, São Paulo. Boi. Rés. Exp., p. 301-302.

GREEN, J.C. 1992. Proterozoic rifts. In: Proterozoic Crustal Evolution. Condie, K.C. Ed. Elsevier. 490p.

GUELORGET, O. \& PERTHUISOT, J.P. 1983. Lê Domaine paralique: Expressions géologiques, biologiques et économiques du confinement. Travaux du Laboratoire de Géologie. Presses de FEcole Normale Supérieure. Paris, $136 \mathrm{p}$.

JACKSON, T. A. 1975. "Humic" matter in the bitumen of pre-Phanerozoic and Phanerozoic sediments and its paleobiological significance. American J. of Science. 275: 906-953.

JARDIM DE SÁ, E.F. 1984. A evolução Proterozóica da Província Borborema. In: XI Simp. Geol. Nordeste, Recife, Atas... 1:297-316.

JARDIM DE SÁ, E.F., KAWASHITA, K. \& MACEDO, M.H.F. 1986. Supracrustais monocíclicas no extremo oeste do Rio Grande do Norte. In: XII Simp. Geol. Nordeste, João Pessoa, Atas..., p. 62-72

JARDIM DE SÁ, E.F. 1994. A Faixa Seridó (Província Borborema, NE do Brasil) e o seu Significado Geodinâmica na Cadeia Brasiliana/F'anAfricana. Brasília - UNB. Tese de Doutorado. 803 p (Inédito).
McREATH, I. - 1992 - Diversidade geoquímica de roches meta-ígneas do Cinturão de Orós (Ceará) e implicações tectônicas. In: XXXVII Congr. BRAS. Geol. SBG/SP, São Paulo, Boi. Rés. Exp. p. 34-35

MACEDO, M.H.F.; Sá, J.M. \& KAWASHITA, K. 1988. A idade da Faixa Orós: dados preliminares. Rev. BRAS. Geoc., 18(3):362-368.

MENDONÇA, J. C. G. S \& BRAGA, A.P.G. 1987. As faixas vulcano-sedimentares de Orós e Jaguaribe: um greenstone belfl Rev. BRAS. Geoc., 17(3):225-241.

MONIÉ, P.; CABY, R. \& ARTHAUD, M. Timing of the neoproterozoic Brasiliano orogeny in northeast Brazil: ${ }^{\wedge} \mathrm{Ar} / \wedge \mathrm{Ar}$ ages and petrostructural data from Ceará -Precambrian Research (no prelo).

PARENTE, C.V. 1995. Géologie et paléogégraphie d'une plate-forme à - évaporites et magnésite d'âge protérozoique (2 Ga): lê cadre géotectonique initial de Ia ceinture mobile Orós dans Ia région d'Alencar (Ceará-Brésil). Thèse de Doctorat de TUniversité de Nantes. 306p (inéd.).

PARENTE, C.V. \& GUILLOU, J.J. 1995a. Geologia e paleogeografia dos depósitos de magnesita de idade proterozóica (2Ga) da região de Alencar (Ceará). In: XVI Simp. Geol. Nordeste. Workshop Província Borborema. Recife. Atas... No 14,2:428-432.

PARENTE, C.V. \& GUILLOU, J.J. 1995b. Petrografia, química e génese dos depósitos de magnesita de idade precambriana da região de Alencar, Ceará. In: XVI Sim. Geol. Nordeste. Recife. Atas... Boi. 14,1: 54-57.

SÁ, J.M.; BEZERRA, F.H.R.; MACEDO, M.H.F. \& PEREIRA, R. 1988. Middle Proterozoic supracrustals and Brasiliano orogeny in the southeast Ceará state: a monocyclic evolution. In: VII Congr. Latino-Americ. GeoL., Belém, Brasil, 1:35-48.

SÁ, J.M. 1991. Evolution geodynamique de Ia ceinture protérozoique d'Orós, Nord-Est du Brésil. Thèse de doctorat de 1'Université de Nancy 1,117p (Inéd.).

SÁ, J.M. \& BERTRAND, J.M. 1992. Transpressão dextral no sudeste do estado do Ceará, Província Borborema. XXXVII Congr. BRAS. Geol. São Paulo. Boi. Rés. Exp., p. 368-370.

SÁ, J.M.; McREATH. I. \& LETTERRIER, J. 1995. Petrology, geochemistry and geodynamic setting of Proterozoic igneous suites of the Orós fold belt (Borborema Province, Northeast Brazil). J. South Amer. Earth Sc., 8(3/4):299-314.

SANTOS, E. J. \& BRITO NEVES, B.B. 1984. Província Borborema. In: $O$ Precambriano do Brasil F.F.M. de Almeida \& Y. Hasui (eds.), Ed. Blucher, Brasil, p 123-186

SANTOS, E.J; COUTINHO, M.G.; COSTA, M.P. de A. \& RAMALHO R. 1984. A Região de dobramentos Nordeste e a Bacia do Parnaíba, incluindo o Cráton de São Luís e as Bacias Marginais, In: Geologia do Brasil, SCHOBBENHAUS C. Ed., DNPM/DGM. p 131-189.

SENGOR, A.M.C. \& BURKE, K. 1978. Relative timing of rifting and volcanism on earth and its tectonic implications. Geophysical Research Letters, 5:419-421.

VAN SCHMUS, W.R.; BRITO NEVES, B.B.; HACKSPACHER, P.; BABINSKI, M.; FETTER, A. \& DANTAS, E. 1995a. Neoproterozoic and late mesoproterozoic sedimentary and vocanic sequences in the Borborema province, NE Brazil. In: XVI Simp. Geol. Nordeste. WorkShop Província Borborema. Recife. Atas... № 14, 2:391-393.

VAN SCHMUS, W.R.; BRITO NEVES, B.B.; HACKSPACHER, P. \& BABINSKI, M. 1995b. U/Pb and Sm/Nd geochronologic studies of the Eastern Borborema Provinces, Northeastern Brazil: initial conclusions. J. South Amer. Earth Sc., 8 (3/4):267-288.

VAUCHEZ. A; NEVES, S.; CABY, R.; CORSINI, M.; EGYDIO-SILVA, M.; ARTHAUD, M. \& AMARO, V. 1995. The Borborema shear zone system, NE Brazil. J. South Amer. Earth Sc., 8 (3/4):247-266.

WINDLEY, B.F. 1984. The evolving continents. 2. ed. New York, Willey, 399 .

MANUSCRITO A867

Recebido em 31 de agosto de 1996

Revisã o do autor em 30 de novembro de 1996 Revisã o aceita em 15 de janeiro de 1997 